\title{
How do different models of PDP influence the embedding of e- Portfolios?
}

\section{Louise Frith}

University of Kent, UK

\section{Abstract}

This paper examines how e-Portfolios have been used in relation to three different models of Personal Development Planning (PDP). It begins with a brief description of the context of the study at the University of Kent. Then, using Clegg and Bradley's (2006) models of PDP, it identifies three case studies to review: Social Work (the professional model), Sports Studies (the employability model) and Physics (the academic model). The discussion centres on what has been learned from these case studies in relation to PDP practice and embedding of e-Portfolios. The paper will be of interest to academics and curriculum developers introducing e-Portfolios to support various models of PDP.

Key words: assessment; models of PDP; reflective learning; staff development.

\section{Introduction}

The University of Kent's PDP practice was reviewed in 2006 (Frith, 2006). This reported existing PDP practice in departments. The review noted that rich and diverse PDP practice was present in all programmes of study but was sometimes so embedded that it was difficult for students to discern. This lack of discernment was interpreted by the university as a potential vulnerability because the National Student Survey asks students three PDP questions relating to self-efficacy, communication skills and problem-solving. Therefore, in 2006 the university's Learning and Teaching Board (LTB) agreed to make PDP more visible whilst retaining a discipline-specific approach.

Kent's PDP support in 2006 involved a series of online, generic questionnaires and template word documents on subjects such as skills audits and SWOT analysis. Part of 
the drive towards e-Portfolios was to get away from this bolt-on and generic approach to PDP. Currently the University of Kent's approach to PDP is delivered by departments using subject specific resources with support from the Unit for the Enhancement of Learning and Teaching (UELT). The author is the PDP Co-ordinator, based in UELT.

In recent years, heavier emphasis is being put on equipping students with employability skills. The proposed introduction of the HEAR (Higher Education Achievement Record) will require universities to verify some of the activities which students have been involved in outside their academic studies. Therefore, it is more important now than it was at the beginning of this pilot project (in 2006) that the university finds ways of helping students to make sense of all their university experiences. It is no longer enough for a student just to list the things that they have done at university. They also need to construct a convincing narrative about the transferability of those experiences for employment purposes. Students will increasingly need help with this process.

The University's Learning and Teaching Board agreed that introducing e-portfolios would help facilitate elements of PDP such as gathering and showcasing evidence, reviewing and ordering, reflective writing, social learning and action planning. E-portfolios have the potential to provide a truer picture of the student's skills and their capacity to capture and learn from their 'learning journey'. E-portfolios also appear to allow an individual approach so that each discipline, and within that each student, can use it differently. The university chose to pilot PebblePad e-Portfolio software. This provides students with a private, personal, online space to record and reflect on their development. Initially 1000 licences were bought so that the software could be piloted. To date the software has been used in 13 academic departments. This study focuses on three because they represent one from each of the three models of PDP identified below.

The three models of PDP which Clegg and Bradley (2006) identify are helpful in understanding why some academic departments have been quick to embed e-portfolios and are comfortable with the software, whereas others have found embedding e-portfolios a much longer and more problematic process. For their analysis, Clegg and Bradley draw on the work of Barnett (2000) and Moore (2001) who identified two directions which courses can face; either projectional, outward facing to employers and the economy, or introjectional, facing inwards to the discipline and the academy. Clegg and Bradley 
position the professional and employability models in the outward facing group whereas the academic model tends to face in.

The professional model is defined as programmes of study which teach the development of specific professional competencies; for example, Teacher Training, Health Care and Social Work. Professions have strong boundaries and a tradition of reflective practice. They have also used professional competency portfolios in assessment for many years. The employability model describes programmes which do not necessarily lead to a specific professional career but which are strongly projectional (outward facing) (see Barnett, 2000; Moore, 2001). They are more generic and have looser boundaries than professional courses. Examples of this model include Sports Studies, Business Studies and Computer Science. Students on these types of programmes often need their degree to gain specific employment but reflective practice may be absent. The academic model refers mainly to Humanities subjects and Pure Sciences, for example, History, English and Physics. Here the focus is introjectional based on the needs of the discipline rather than the needs of future employers. In these subjects staff generally do not see employment as the focus for the degree as students follow varied career paths; staff aim to create a graduate rather than a professional. In these subjects, PDP focuses on enabling students to recognise their learning process and practice skills necessary for development in the discipline.

\begin{tabular}{|c|c|c|}
\hline & \multicolumn{2}{|c|}{$\begin{array}{l}\text { Moore (2001), Barnett (2000) } \\
\text { Identify two directions in which } \\
\text { programmes of study can face }\end{array}$} \\
\hline & $\begin{array}{l}\text { Introjectional } \\
\text { Facing inwards }\end{array}$ & $\begin{array}{c}\text { Projectional } \\
\text { Facing outwards }\end{array}$ \\
\hline \multirow{2}{*}{$\begin{array}{l}\text { Clegg \& Bradley (2006) } \\
\text { Identify three models of PDP which can } \\
\text { be placed either into the introjectional or } \\
\text { the projectional category. }\end{array}$} & $\begin{array}{c}\text { Academic: } \\
\text { Physics, History, } \\
\text { English }\end{array}$ & $\begin{array}{l}\text { Professional: } \\
\text { Social Work, } \\
\text { Teaching, Health } \\
\text { Care } \\
\end{array}$ \\
\hline & & $\begin{array}{l}\text { Employability: } \\
\text { Sports Studies, } \\
\text { Business Studies }\end{array}$ \\
\hline
\end{tabular}

Figure 1. Clegg and Bradley's three models of PDP based on earlier work of Moore and Barnett. 
This paper outlines the methodology for the study at Kent. It then describes three case studies, one from each of the models: the Professional model (Social Work), the Employability model (Sports Studies), the Academic model (Physics). Discussion of four points of learning emerges. The first is the strength of the discipline specific approach. The second is the debate about whether to award credit for students' PDP. The third is the importance of creating authentic student experiences for meaningful reflection to occur. Finally, this work has exposed a staff development need to learn how to set and mark reflective tasks.

\section{Methodology}

This paper is part of a wider review of the use of e-portfolios at Kent. All the departments which used the software were asked to provide feedback on their experiences. Data has been gathered through a variety of ways: statistical data that is generated by the software, such as how often students use the software and which tools they use the most; staff views sought through questionnaires and structured interviews; and students' views gathered through questionnaires, focus groups and structured interviews with students. This paper focuses on the qualitative data gathered through interviews, focus groups and questionnaires. The subjects chosen to investigate for this paper were selected on the basis that they represent one of each of the models identified by Clegg and Bradley. All these departments requested the support of UELT'S PDP co-ordinator to embed PDP or eportfolios. Her role is to support the department in embedding e-portfolio technology or PDP activities and to evaluate this process.

\section{Case study 1: Social Work}

Social Work, as with many other professional programmes of study, makes close connections with the professional requirements. For example, the Social Work programme at Kent complies with the requirements of the Department of Health, TOPSS (The Training Organisation for the Personal Social Services) and the GSCC (General Social Care Council). These bodies set out how many days of practice students must complete in order to qualify, and they also write the guidance on the assessment of practice. These requirements link with students' process of PDP. The Social Work programme has large 
elements of practice-based learning. In Year 1 students do a ten day placement which they write up for reflection and integration of knowledge and practice. In Year 2 and 3 students must complete two 100 day placements which are required for registration as a Social Worker. This experience is written up by students in a document called 'Assessment of Practice'. This is a collaborative piece of reflective writing by the student with input and feedback by the practice assessor and the academic tutor.

The Social Work department was one of the first to use e-portfolios at Kent. They quickly went from piloting the use of e-portfolios on a voluntary basis in year 1 to requiring all students to use the e-Portfolio and awarding significant credit for the e-Portfolio in year 2. E-portfolios are now completely embedded in the School of Social Work. All students and their practice assessors are given training in how to use e-Portfolios and all students are expected to submit a collaborative e-portfolio of their competencies in Social Work. Students cannot share their webfolio outside of their programme of study because much of their work is confidential. The screen shot below (Figure 2) shows an empty webfolio template which the students populate with their experiences and reflections.

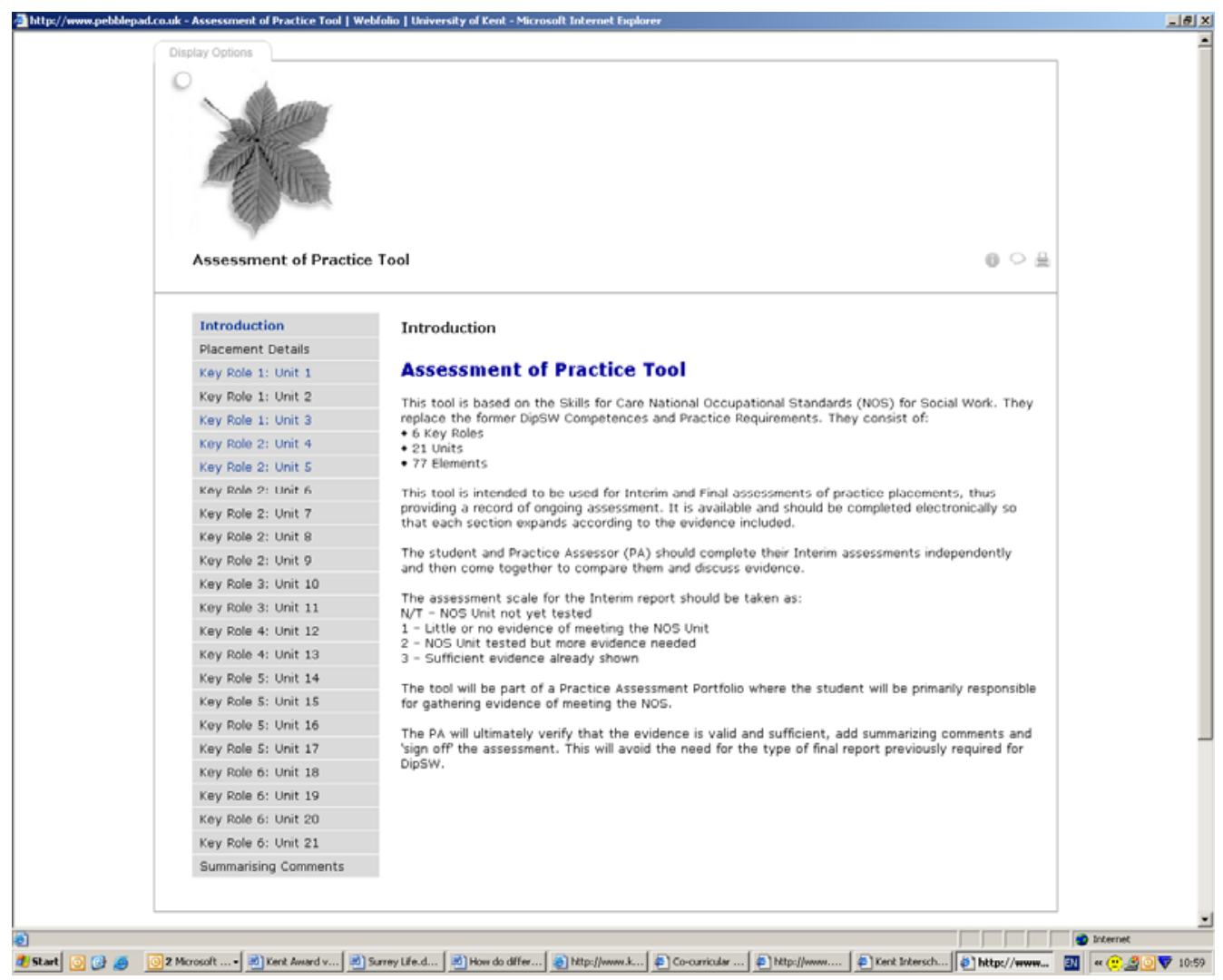

Figure 2. Screen shot of Social Work Assessment of Practice e-Portfolio template. 
Feedback from lecturers, students and practice assessors on this programme has been positive as it has solved a previous practical problem of version control, i.e. the problem of three stakeholders working from three slightly different versions of the same document. The only issues that have caused minor difficulties have been technical. Some students and some practice assessors were initially resistant to learning and using a new technology. Some of the students' negative comments were recorded through questionnaires:

I find it difficult to use because the font is smaller than I am used to... I have experienced difficulties signing in to the software...it's a bit slow...it takes ages to upload information.

These issues have been easy to resolve and the technology is now fully integrated into the Social Work programme. There have been no issues about what PDP is, or what to assess. The feedback that students receive is both formative and summative assessment of practice. The e-Portfolio was applied to an existing assessment of practice and it was generally deemed to be an improvement to practice. The Director of Studies commented:

This is an interesting addition to our work and has attracted the attention of other Social Work departments nationally.

\section{Case study 2: Sports Science}

In Sports Studies programmes PDP is located within modules. Study skills are introduced throughout year 1 modules and then in years 2 and 3 there are practical modules in which students design and implement a project. This is assessed by a written report of their experience. However, reflection on the process of skills development or the experiences of practical work was absent. A Sports Studies lecturer said:

Previously there was no requirement for formal reflection. The e-Portfolio gives students the facility to record their experiences and learning from practical work.

Therefore the Sports Studies department were initially keen to try to use e-portfolio software and it was offered to students as a way of reporting their work on one module. 
Students used the module to show how they would organise a sports event for a special population. The students had to show evidence of a variety of competences such as project planning, budgeting, health and safety awareness. Although students were encouraged to use the software it was not compulsory and no extra marks were awarded for use of an e-Portfolio. This meant that usage was patchy but those students who used the software liked it:

It helped me to reflect because it made me organise and order my work. I think it helps people who are not naturally organised to order their work so it also helps to form good study habits.

Students said that they would welcome the e-Portfolio being made compulsory because then it would be better supported:

PebblePad is useful for reflecting on work and presenting it, but we need more support from the department on how to use the software.

A student who did not use the e-portfolio said in a focus group session:

If we had been able to get extra marks for it I would have used it but I was really busy with the project and it wasn't worth it.

Lecturers noted that it was particularly useful for the recording of practical work. Lecturers also see the potential that it has for raising the profile of students' reflections on the process of their learning. When staff were asked if they would use e-Portfolio software again, they responded positively:

Yes, particularly to record experiences of practical work and to help students see their own development resulting from practical experience.

\section{Case study 3: Physics}

The Physics department has been enthusiastic to engage with PDP but fitting it into the curriculum has been difficult. Students' experience of PDP is through a generic online 
resource called Keynote which uses a series of Word documents to prompt students to record their generic skills development. The department is small so there is the opportunity for face-to-face tutor support on students' progression but this is not a formal process so it usually responds to crisis rather than supports students' learning development.

In an initiative to make PDP more discipline-focused the department looked first at the requirements of the discipline through ascertaining the Threshold Concepts (Meyer and Land, 2003) in the discipline. Threshold Concepts are the parts of the curriculum that are most memorable, transformative, interrogative, or troublesome. In focus groups, Physics students noted the importance of applied and practical science for their motivation and memory, as well as to help them to make links with the real world. They said:

Physics modules are more memorable because they are applied to something real that we can relate to... applications of what we have learnt such as ElectroMagnetics, Forensic Science, Medical Physics, Space Craft Design and Rocket Science, build a bridge between concepts and real life examples.

The Threshold Concepts approach encourages students to reflect on the most troublesome and potentially transformative parts of learning. There are similarities between a focus on the Threshold Concepts on a subject and the Critical Incidents (Brookfield, 1987) in a person's learning. The difference is the first focuses on the difficulties of the subject and the second focuses on the experiences of the learner. The Threshold Concepts identified are now being used to 'scaffold-in' a series of reflective questions after threshold learning has taken place. The questions below are an example. They require students to reflect on their development as a result of studying Quantum Mechanics. 


\section{Studying this module may have altered your ideas about Quantum Mechanics.}

1. Has your understanding of matter changed after studying Quantum Mechanics?

2. Has your understanding of energy changed after studying Quantum Mechanics?

3. Which theorems of Quantum Mechanics do you think are most helpful for solving problems?

4. Which applications of Quantum Mechanics do you think are most interesting?

5. Which concepts of Quantum Mechanics do you think are most difficult to understand?

\section{Figure 3. Reflective Questions for Quantum Mechanics module.}

These questions are aimed at supporting students' awareness of their own personal and academic development through engagement with their subject. The intention is for this to be completed by students in an e-Portfolio in the academic year 2010/11.

E-portfolios in Physics have not yet been introduced; however, a lot of preliminary work has been done in the department about supporting students' reflection on their studies. Lecturers in the department are aware that reflective learning is not currently part of their repertoire, as a professor of Physics commented:

Before we began this process [PDP] students did not reflect on their academic development at all.

The intention is to introduce a portfolio and blog tool to support this work and to give the students' reflection a vehicle for feedback and assessment. Although marking students' reflections on learning is acknowledged by lecturers as problematic, they are realistic that without some credit students will not engage with the process at all. The assessment of students' reflective portfolios is planned to be formative with the aim of encouraging students' meta-cognitive processes. This is information which is currently not made known by other assessment methods (Murphy, 1997). 


\section{Advantages of a discipline specific approach}

The CRA (2005) recommend in their guidance for busy academics that PDP is likely to be most effective when it is embedded into a programme of study. This approach is supported in Clegg and Bradley's (2006) work in which they recommend that (PDP) initiatives are more likely to succeed if they engage positively with teacher beliefs. The University of Kent has instinctively taken a discipline-specific approach to PDP so practice is varied. From the three case studies outlined above the arguments for a discipline-focussed approach to PDP are clear. Each example shows a very different academic culture, from Social Work in which PDP is driven by external professional requirements, Sports Studies which is beginning to use PDP to encourage students' reflection on practical projects, to Physics which interprets PDP as a way to help students understand the most difficult aspects of their learning. This experience again chimes with Clegg and Bradley's position in which they say that PDP support and development should aim to understand the views of different stakeholders about the place of PDP in the curriculum. They also warn that PDP may 'disturb' academic practices in some disciplines more than others.

From the perspective of educational development the discipline-specific approach has a clear advantage because it means that conversations about PDP start with the demands of the discipline rather than the demands of PDP. The discipline-specific approach allows PDP activities to be embedded in the curriculum at points when they will have most relevance to the students' learning. Commitment to discipline-specific PDP was a significant factor in choosing the Threshold Concepts (Meyer and Land, 2003) approach to implementing PDP in the School of Physics. Allowing each department to find their own approach to PDP and the use of e-Portfolios takes longer than imposing a university-wide approach to PDP. However, it is more likely to keep the disciplines intact, which may result in PDP being a much more integrated process.

\section{Assessment of PDP}

Awarding credit for PDP has been much debated (Clegg, 2004; Edwards, 2005, p.6; Brennan and Shah, 2003, p.7). Arguments for the assessment of e-Portfolios are made by Van Sickle et al. (2005) who state that assessment of e-Portfolios will be beneficial because it will increase student reflection and make reflection on experiences gained as 
part of their programme of study more visible. In addition, Race (2001) says assessment is a fundamental element of learning and that students and staff pay most attention to assessment. This point is confirmed in the research, for example, a lecturer from the School of Physical Sciences said:

I have learnt a lot about how students engage with PDP. There must be a concrete incentive such as credits to ensure student engagement.

Therefore, if PDP is to be adequately supported it has to be assessed both formatively, to promote students' learning from the process, and summatively, to ensure engagement of staff and students. This may also have the effect of getting departments to clarify what they mean by PDP, because in order to assess something it needs to be made explicit. Murphy (1997) claims that by encouraging students' meta-cognitive processes, information which is currently not made known by other assessment methods becomes clearer. Eportfolios can help in this process due to their multiple levels. There are some things which a student can keep behind the scenes, for example, peer-blogging which may be useful for formative and peer feedback, and there are other aspects such as the presentational portfolio which lend themselves to showcasing skills and can be summatively assessed.

\section{Creating authentic experiences}

All the models of PDP require staff to provide students with concrete, authentic experiences on which to base their reflection. This is an essential starting point for reflection. The Social Work placement is rich with concrete experiences and plenty of challenges for students to reflect upon, and they are supported in this by their tutor and practice assessor. Reflection is an essential element of learning to be a Social Worker. The Sports Studies module is also practical; students are given a list of competencies which they have to provide evidence for their engagement with during their project. Students are expected to identify Critical Incidents (Brookfield, 1987) and reflect upon these. For Physics students practical experiences mainly come from lab work or from applying theory to practical situations such as space craft technology or medical equipment. An emphasis on the authentic concrete experiences which students have during their programme of study will help academics to identify opportunities to promote and support students' PDP. 


\section{Staff development in reflective learning}

Finally, introducing a new piece of software to three very different programmes of study has exposed some interesting staff development issues. The practical issues of training staff and students to use e-Portfolio software have been relatively straightforward. The main areas for staff concern have been creating varied authentic assessments to give students concrete experiences to reflect on, and setting and marking of reflective activities. For Social Work this has not been an issue as the programme is very practical and academics are already used to supporting reflective learning. Sports Studies provides students with authentic concrete experiences but staff are unfamiliar with the use of reflection for academic purposes. Whereas the School of Physics really needs to address the first issue of creating authentic experiential assessment before it can start to support students' reflective learning. The issue of supporting reflective learning was raised in one of the structured telephone interviews with Sports Studies staff:

We would value more support on getting students to understand the concept of PDP and on asking reflective questions of them.

Therefore this has required significant staff development for lecturers on these programmes of study. There is now guidance on the university's PDP website for academics on many issues related to implementing PDP, experiential learning and reflective learning, such as creating authentic practical assessment tasks, setting reflective questions, assessing e-Portfolios, setting up collaborative e-portfolios and using blogs to support students' reflection. This was an unforeseen outcome of implementing e-Portfolios and more work needs to be done in this area.

\section{Conclusion}

It has been clear from analysing these three disciplines, and the embedding of PDP/ePortfolios in them, that different models of PDP definitely have an impact on the success and ease of the process. In a professional model of PDP, such as Social Work, the process was quick and easy because issues such as assessment of reflective practice, authentic tasks for reflection and staff expertise in reflective practice were well established. 
The e-portfolio simply replaced a previous similar system. Apart from some initial issues with learning about and using new technology, the embedding was a smooth process.

In Sports Studies the process was slower because initially no credit was given to students for engagement in the reflective process and staff were not confident in how to set and mark reflective tasks. However, both staff and students saw the benefits of using the ePortfolio software to support students' PDP in terms of capturing an aspect of their learning that was previously lost. Students noted that it helped them to develop good habits associated with study, such as recording experiences and reflecting on them. They also said that they would welcome more support in using the software, and acknowledged that this would probably come if use of the software and PDP tasks such as reflection and blogging were made compulsory. Lecturers on the module recognised that the e-portfolio was making aspects of learning on the module which had previously been tacit become more explicit. They welcomed this development because it helps students to recognise their learning process.

Physics staff were not confident with elements of PDP such as reflective learning. In addition to this barrier, there were issues about the lesser emphasis given to practical and applied approaches to learning as opposed to theoretical, knowledge-based approaches. Through discipline-focussed discourse, enabled by the Threshold Concepts approach, a way of supporting PDP in the study of Physics is being established. The process of change is ongoing, and it remains to be seen whether an e-Portfolio will be a useful addition to the department's response to PDP. However, the acceptance of more practical approaches to learning Physics has been established.

This study indicates that embedding PDP and e-Portfolios into all programmes of study requires a change in pedagogy. It also supports Clegg and Bradley's (2006) observation that PDP may disturb the academic practices in some disciplines more than others. However, it is clear that disciplines can provide bespoke PDP opportunities by designing authentic, experiential assessment tasks which are assessed both formatively and summatively to ensure student engagement and learning. Reflective learning supports this and helps students to recognise the transferability of some of the skills they are developing. The role of educational developers in this is to support academic departments to change assessment practices and understand reflective learning. 


\section{Acknowledgement}

This paper is an outcome of the National Action Research Network on researching and evaluating Personal Development Planning and e-Portfolio practice project (2007-2010). The project was led by the University of Bolton in association with the University of Worcester and Centre for Recording Achievement, and in national collaboration with the University of Bedfordshire, Bournemouth University and University of Bradford. The project was funded by the Higher Education Academy, National Teaching Fellowship Project strand. More details about the project can be found at: http://www.recordingachievement.org/research/narn-tree.html.

\section{References}

Barnett, R. (2000) 'Supercomplexity and the curriculum', Studies in Higher Education, 25(3), pp. 255-265.

Brennan, J and Shah, T. (2003) Report on the implementation of Progress Files. London: Centre for Higher Education Research and Information.

Brookfield, S. (1987) Developing critical thinkers. San Francisco, CA, US: Jossey-Bass.

Clegg, S. (2004) 'Critical readings: progress files and the production of the autonomous learner', Teaching in Higher Education, 9, pp. 287-298.

Clegg, S. and Bradley, S. (2006) 'Models of PDP: practice and processes', British Educational Research Journal, 32(1), pp. 57-76.

CRA (2005) Guide for busy academics no. 1: personal development planning. Available at: http://www.business.salford.ac.uk/intranet/PDP/creativity/download.php?id=60 (Accessed: 20 April 2010).

Edwards, G. (2005) Connecting PDP to employer needs and the world of work. York: HEA. 
Frith, L. (2006) PDP University of Kent internal review. Available at:

http://www.kent.ac.uk/uelt/ced/themes/personal-development/ (Accessed: 21 September 2010).

Meyer, J. and Land, R. (2003) 'Threshold concepts and troublesome knowledge (1): linkages to ways of thinking and practising within the disciplines', in Rust, C. (ed.) Improving student learning theory and practice - ten Years On. Oxford: OCSLD, pp. 412-424.

Moore, R. (2001) 'Policy-driven curriculum restructuring: academic identities in transition?', Higher Education Close Up Conference 2. Lancaster University 16-18 July. Available at: http://www.leeds.ac.uk/educol/documents/00001803.htm (Accessed: 27 August 2010).

Murphy, S.M. (1997) 'Who should taste the soup and when? Designing portfolio assessment programs to enhance learning', Clearing House, 71(2), pp. 81-85.

Race, P. (2001) The lecturer's toolkit: a practical guide to learning teaching and assessment. London: RoutledgeFalmer.

Van Sickle, M., Bogman, M.B., Kaman, M., Baird, W. and Butcher, C. (2005) College Student Journal, 39(3), p.497.

\section{Author details}

Louise Frith is the PDP Co-ordinator in the Unit for the Enhancement of Learning and Teaching (UELT) at the University of Kent. Her role is to support the department in embedding e-Portfolio technology or PDP activities and to evaluate this process. 